\title{
Factors of feasibility: an interview study of physicians' experiences of expanded access to investigational drugs in three countries
}

\author{
Stefan F. Vermeulen (ID ${ }^{1}$, Marjolijn Hordijk${ }^{1}$, Nikkie Aarts ${ }^{1} \&$ Eline M. Bunnik ${ }^{1 凶}$
}

Seriously ill patients who have exhausted all approved treatment regimens and who cannot be enrolled in clinical trials may resort to expanded access programmes in order to gain access to unapproved, investigational drugs. It seems that in some countries, expanded access to investigational drugs is offered in clinical practice on a more routine basis than in other countries. This study is the first to investigate the experiences of physicians with expanded access to investigational drugs in different healthcare systems, with a focus on factors that facilitate or hinder expanded access. Semi-structured interviews $(n=36)$ were carried out with medical specialists in the Netherlands $(n=14)$, Turkey $(n=9)$ and the United States of America $(n=13)$, and analysed thematically. This study identifies five sets of factors pointed out by physicians that determine the degree to which expanded access to investigational drugs is deemed feasible in clinical practice: the suitability of investigational treatments, the application process, hospital policies, support by pharmaceutical companies, and funding and reimbursement arrangements. Based on the interviews conducted, we conclude that, while legally allowed and technically possible, expanded access is not always feasible for-and not always considered an option by-treating physicians. This is mainly due to lack of familiarity with expanded access, the extensive time and effort required for the application process, willingness or ability of pharmaceutical companies to supply the drugs, and funding issues.

\footnotetext{
${ }^{1}$ Department of Medical Ethics, Philosophy and History of Medicine, Erasmus MC, University Medical Centre Rotterdam, Wytemaweg 80,3015 CN Rotterdam, The Netherlands. 凶email: e.bunnik@erasmusmc.nl
} 


\section{Introduction}

fter exhausting all approved medical treatments for patients who are suffering from serious or life-threatening diseases and ineligible for clinical trials, physicians mayunder strict conditions-resort to expanded access to unapproved, investigational drugs: the process of prescribing investigational drugs that are not (yet) registered by regulatory authorities, outside of the context of clinical trials (Falit and Gross, 2008; Darrow et al., 2015; Caplan et al., 2019), as a final therapeutic option. In most countries, expanded access can only be granted when patients satisfy three criteria: (a) they must be suffering from serious or life-threatening diseases, (b) they must have exhausted all applicable approved alternatives and (c) they must not be eligible for clinical trials (either because there are none in which they can reasonably or logistically participate, or because they do not meet the in- or exclusion criteria). However, exact procedures differ internationally (Kimberly et al., 2017). Also, there are significant differences in uptake of expanded access programmes across countries, ranging from 100 to 200 applications per year in the Netherlands (De Visser, 2016) and 1000 in the United States (Jarow et al., 2016), to around 21,000 in France (ANSM, 2019), and 25,000 in Turkey (Koçkaya et al., 2014). To date, little is known about the factors affecting uptake from an international perspective or from the perspective of treating physicians engaging in expanded access to investigational drugs.

Treating physicians play major roles in expanded access to investigational drugs, by identifying expanded access programmes, verifying eligibility criteria, estimating risks and benefits, informing patients about expanded access, and carrying out request procedures. The process extending from identification of opportunities for expanded access to administration of an unapproved drug is complex, and poses significant challenges to physicians, including reimbursement and liability issues and administrative burdens (Falit and Gross, 2008; Darrow et al., 2015; Watson, 2017; Bunnik and Aarts, 2021). Ethical concerns are at play, as well, and include the lack of safety data, the absence of strict in- and exclusion-criteria for expanded access (contrary to clinical trials) per its status as an ultimum remedium (Darrow et al., 2015; Gertel, 2017; Bunnik et al., 2018), and the often rather limited clinical benefit of most newly developed drugs (Wieseler et al., 2019). Nonetheless, expanded access programmes are put in place to offer potential benefit to patients in exceptional circumstances, in which they have run out of approved alternatives, as a last resort (Salzman et al., 2018; Chapman et al., 2019). What are the factors that hinder or facilitate this process? How do doctors decide whether or not to pursue expanded access to investigational drugs for their patients?

Only limited empirical research has been carried out into physicians' perspectives on facilitating factors for expanded access to investigational drugs, with the little research done focussing on specific subpopulations of physicians (Moerdler et al., 2019; Gerasimov et al., 2020; Bunnik et al., 2021; Smith et al., 2021). To our knowledge, no studies have investigated physicians' experiences with expanded access to investigational drugs from a global perspective. We have found no international comparative studies of practices of expanded access to investigational drugs, nor any qualitative research on physicians' experiences with expanded access in different countries. This study discusses the results of an interview study aimed at qualitatively identifying factors that, in the experience of physicians, hinder or facilitate the process of expanded access to investigational drugs in clinical practice in different healthcare systems. In order to capture a wide range of experiences of factors restricting or encouraging physicians to resort to expanded access, the interview study was conducted amongst physicians in both our home country, the Netherlands, and in parts of two other countries with different healthcare systems, different regulatory routes to expanded access, and different reimbursement standards. We selected Turkey, which has a particularly high uptake of expanded access, and the United States (US), which, in recent years, has seen a considerable national public debate on expanded access in the run-up to legislative changes culminating in US President Trump's passing of the federal Right-to-Try Act into law in May 2018 (Agarwal and Saltz, 2020).

\section{Healthcare systems}

The healthcare systems in the Netherlands, Turkey and the US differ vastly (see Table 1). The Netherlands has a system of universal health coverage with mandatory private health insurance for a healthcare package as defined by the government (Kroneman et al., 2016), in which out-of-pocket payment for health care is not customary. The US has a hybrid multi-payer system that includes a large private sector (Rice et al., 2020). Turkey has a single-payer public system, yet a large additional private sector (Tatar et al., 2011). Secondly, as seen in Table 1, the three different countries have vastly distinct annual healthcare expenses per capita, ranging from 248 US Dollar in Turkey to 11,172 US Dollar in the US (CM\&MS, 2019; CBS, 2020; OECD, 2020).

\section{Expanded access systems}

In addition to differences in healthcare systems, which may possibly influence physicians' stances towards the provision of unapproved treatments, the regulations for expanded access to investigational drugs differ significantly between countries. Neither the Netherlands nor the US have routine reimbursement in place for expanded access, in contrast to Turkey, where the healthcare system provides routine financial compensation for the use of investigational treatments (Vural et al., 2012; Koçkaya et al., 2014). While all three countries offer two general routesnamed-patient programmes for individual patients (or small groups of patients) (see Table 2) and compassionate use programmes for (intermediate-size or large) groups of patients (see Table 3) - the exact regulations differ considerably. Below we will give a brief overview of the regulations and practices of expanded access in these three countries.

The Netherlands. In the Netherlands, pharmaceutical companies can set up compassionate use programmes after successful completion of phase III clinical trials, to be assessed by the national Medicines Evaluation Board (CBG, 2021). Between 2010 and 2020, 29 compassionate use programmes were approved (CBG, 2021). Physicians can apply for named-patient use after completion of phase I or IIa clinical trials. Requests must be approved by the Health Inspectorate (IGJ, 2020a, 2020b), which is estimated to approve $\sim 100-200$ named-patient programmes-for individual patients or small groups of patients-per year (De Visser, 2016). The named-patient regulatory route is also used to import drugs that are not investigational, and have been approved elsewhere, in case, for instance, of temporary delivery shortages. Approval by an ethics review committee is not required. In theory, pharmaceutical companies can charge patients for expanded access, but in practice, companies supply the drugs free of charge. Expanded access is not covered by national health insurers. Patients will generally not be charged for ancillary costs, as outof-pocket payment in hospitals is not considered ethically acceptable. 
Table 1 Some characteristics of healthcare systems in the Netherlands, Turkey and the United States.

\begin{tabular}{|c|c|c|c|}
\hline & The Netherlands & Turkey & United States \\
\hline Inhabitants & $>17$ million & >80 million & >325 million \\
\hline Health care system & $\begin{array}{l}\text { - universal health care } \\
\text { - multi-payer } \\
\text { - very small private sector }\end{array}$ & $\begin{array}{l}\text { - universal health care } \\
\text { - single payer } \\
\text { - large private health } \\
\text { care sector }\end{array}$ & $\begin{array}{l}\text { - hybrid system } \\
\text { - multi-payer } \\
\text { - managed care programmes } \\
\text { - large private health care sector }\end{array}$ \\
\hline Health insurance & $\begin{array}{l}\text { - mandatory } \\
\text { - private }\end{array}$ & $\begin{array}{l}\text { - mandatory } \\
\text { - public }\end{array}$ & $\begin{array}{l}\text { - national health insurance programmes for specific } \\
\text { groups (Medicaid, Medicare) } \\
\text { - private }\end{array}$ \\
\hline $\begin{array}{l}\text { Annual health care expenses } \\
(\% \text { GNP) }\end{array}$ & $13.1^{1}$ & $4.2^{11}$ & $17.7^{111}$ \\
\hline Annual health care expenses per & $7118^{\mathrm{IV}}$ & $248^{V}$ & $11,172^{\prime \prime \prime}$ \\
\hline
\end{tabular}

capita (US dollar)

All currencies were converted by the authors at the time of writing. Data from '2019 (CBS, 2020), "2018 (OECD, 2020), III2018 (CM\&MS, 2019), IV 6120 Euro (CBS, 2020), V1904 Turkish Lira (OECD, 2020).

Table 2 Named patient programmes in the Netherlands, Turkey and the United States.

\begin{tabular}{llll} 
& The Netherlands & Turkey & United States \\
\hline Applicability & Post phase Ila & Mostly drugs that are approved in & Post phase II \\
& other countries & Pharmaceutical companies, patients \\
Financing & Pharmaceutical companies & Social Security Institution & 1000 per yearVIII \\
Uptake & $100-200$ per yearVI & 25,000 per yearVII & Food and Drug Administration (FDA) \\
Oversight & Health and Youth Inspectorate (IGJ) & Ministry of Health & Necessary \\
Evaluation by Ethics Review & Not applicable & Not applicable & \\
Committee & & & \\
\hline VI(De Visser, 2016), VII(Koçkaya et al., 2014), VIII(Jarow et al., 2016). & & \\
\hline
\end{tabular}

Table 3 Compassionate use programmes in the Netherlands, Turkey and the United States.

\begin{tabular}{|c|c|c|c|}
\hline & The Netherlands & Turkey & United States \\
\hline Phase of clinical study & Post phase III & Post phase II & Post phase III \\
\hline Number of patients & Group of patients & Group of patients & $\begin{array}{l}\text { Group of patients (intermediate-size groups or } \\
\text { widespread use) }\end{array}$ \\
\hline Financing & Pharmaceutical companylX & State & $\begin{array}{l}\text { Pharmaceutical company, health insurer, } \\
\text { patient }\end{array}$ \\
\hline Uptake & 29 programmes $2010-2020^{X}$ & 42 programmes $2006-2011 \times 1$ & 20-40 programmes per year $\mathrm{XII}$ \\
\hline Oversight & $\begin{array}{l}\text { Medicines Evaluation } \\
\text { Board (CBG) }\end{array}$ & $\begin{array}{l}\text { Medicines and Medical Devices } \\
\text { Agency (Ministry of Health) }\end{array}$ & Food and Drug Administration (FDA) \\
\hline $\begin{array}{l}\text { Evaluation by Ethics Review } \\
\text { Committee }\end{array}$ & Not applicable & Not applicable & Necessary \\
\hline
\end{tabular}

United States. In the US, physicians can apply with the Food and Drug Administration (FDA) for individual patients past phase II clinical trials, or for intermediate-sized/widespread use-provided that drugs have passed phase III clinical trials, or that there is "compelling data" from phase II clinical trials and patients face an "immediate life-threatening condition" (Jarow et al., 2016; CFR, 2020). Ethics review committees have to approve the use of the drug (Borysowski et al., 2017). The FDA handles over 1000 Investigational New Drug (IND) applications for single patients per year, and approves between 20 and 40 compassionate use programmes per year which may cover single patients to dozens or hundreds of patients (Jarow et al., 2016; FDA, 2020). Pharmaceutical companies are allowed to charge for the direct costs associated with the supply of investigational drugs, and patients can try to have the costs of the drug and any ancillary costs reimbursed through their health insurance (FDA, 2016; Van Norman, 2018). In addition, the federal Right-to-Try act, signed into law by US president Trump in May 2018, allows pharmaceutical companies to supply unregistered drugs to patients without approval by the FDA (Agarwal and Saltz, 2020). The 21st Century Cures act demands pharmaceutical companies to publicly provide information about their policies for expanded access (Goble, 2018), and monitor patient demand for unapproved treatments. While aiming to make investigational drugs available to a wider range of patients, neither act obliges companies to make investigational drugs available to patients (Rubin, 2015; Holbein et al., 2015; Bateman-House and Robertson, 2018) or treating physicians to pursue or collaborate with expanded access requests for their patients.

Turkey. With 25,484 prescriptions for unapproved drugs issued via expanded access programmes in 2010 (Koçkaya et al., 2014), 
use of expanded access seems far more common in Turkey. Physicians apply for named-patient access via the Ministry of Health, mainly for drugs that have already been approved in the US or in the European Union, due to a commonly occurring time lag between marketing authorization in other countries and marketing authorization in Turkey. There was a median gap of 573 calendar days to submission with the Turkish regulatory authorities, with an additional 644 calendar days for final approval between 2012 and 2015 (Mashaki Ceyhan et al., 2018). After evaluation of a named-patient request for expanded access by the Turkish Medicines and Medical Devices Agency (TITCK) of the Turkish Ministry of Health, a reimbursement decision is made by the Social Security Institution (SGK) (Koçkaya et al., 2014). Approval by an ethics review committee is not required. In addition, pharmaceutical companies and treating physicians can apply with the Ministry of Health for state-financed compassionate use for investigational drugs, which have not been approved anywhere in the world but have passed phase II clinical trials. The Ministry ran 42 programmes (for 1247 patients) in the period 2006-2011 (Vural et al., 2012).

\section{Methods}

In order to capture a wide range of experiences with expanded access to investigational drugs in this interview study, we recruited physicians working in different countries, different types of hospitals, and with different medical specialties, who treat patients with unmet medical needs. We conducted semistructured individual interviews with medical specialists in the Netherlands, the United States and Turkey, from a variety of medical specialties including internal medicine, endocrinology, haematology, oncology, neurology/neurosurgery and psychiatry, who worked in community/public hospitals, academic medical centres or private hospitals. Interviews were conducted with the help of an interview guide, an English translation of which is supplied as a Supplement. The interview study was set up in accordance with the COREQ criteria (Tong et al., 2007).

Selection of participants. American and Dutch respondents were selected through purposive sampling via hospital websites or scholarly publications, through the researchers' networks and snowball sampling. We approached dozens of American physicians by e-mail from various departments in various academic and community hospitals in New York City and New York State, and asked if they were willing to meet with us during a 10-day research visit in September-October 2016. Some agreed to participate in the interview study, but were unavailable during our visit to New York, and agreed to be interviewed over Skype afterwards. In addition, we approached physicians in various other American states for Skype interviews, until saturation was reached.

As for this study we sought countries with potentially significantly different expanded access practices, we wished to include physicians from either France or Turkey, because, as said, expanded access to investigational drugs has a high uptake and is routinely publicly funded in these two countries. We selected Turkey for pragmatic reasons, as in Istanbul and Ankara, we could solicit the help of local employees of myTomorrows, an international platform that informs patients with unmet medical needs about investigational treatments (https://mytomorrows.com/en), which was involved in our research project as a private partner. Involvement of a private partner was a requirement within the Responsible Innovation programme of the Dutch Research Council, which funded our research project. For our interview study, the Turkish team recruited physicians working in two major Turkish cities, Istanbul and Ankara, who had prior collaborations with the platform as well as physicians who did not have such collaborations. The local employees invited physicians working at academic hospitals, community hospitals and private hospitals, to participate in our study, to ensure a broad range of physician experiences.

Interviews. Interviews took place at physicians' work offices or through Skype, were conducted in English or in Dutch, lasted between 45 and 90 minutes, and were conducted by NA and/or EB between December 2015 and December 2016. In the interviews, we discussed physicians' experiences with practices and processes of expanded access, to investigational drugs and their views on physicians' moral responsibilities in relation to expanded access, following the interview guide (see Supplement). The interviews were audio-recorded and transcribed verbatim.

Analysis. A separate analysis of the interviews with Dutch physicians reporting their experiences with and perspectives on expanded access to investigational treatments has been published elsewhere (Bunnik et al., 2021). For the current paper, we conducted a new analysis of the transcripts of the interviews conducted in all three countries, with a focus on the identification of factors facilitating and hampering expanded access in practice. We used a constant comparative method using NVivo version 11 for coding and thematic analysis. Codes were assigned and (re) grouped into themes through multiple readings of the interviews (Bradley et al., 2007; Glaser and Strauss, 2017). The first three interviews were independently analysed by NA and EMB, resulting in the development of a code tree with multiple levels of codes. Discrepancies were discussed until consensus was reached. Remaining interviews were coded by NA. Theoretical saturation was reached after the analysis of the 12th interview and the code tree was no longer adapted. Coded transcripts were re-analysed by SFV and EMB with a particular focus on identifying physicians' experiences of factors that have influenced whether or not -or to what extent-expanded access was feasible in practice, and thus constituted 'an option' for them.

Ethics approval and consent to participate. We received a waiver from the research ethics review committee of Erasmus MC, Rotterdam, the Netherlands (MEC-2016-275), as the research does not fall within the scope of the Dutch Medical Research Involving Human Subjects Act. All interview respondents provided oral informed consent for recording and participation.

\section{Results}

Characteristics of the respondents. We conducted a total of 36 interviews with medical specialists; 14 in The Netherlands, 13 in the USA and 9 in Turkey. Twelve out of 36 interviewees were female $(33.3 \%)$. Interviewees had backgrounds in different specialities, reaching from internal medicine $(n=3)$, oncology $(n=7)$, haematology $(n=15)$, psychiatry $(n=4)$, neurology/ neurosurgery $(n=6)$ to surgery $(n=1$, with $n$ being the number of interviewees in a specific specialty). Interviewees worked in community/public hospitals $(n=9)$, academic hospitals $(n=22)$, or private hospitals $(n=4)$. Full characteristics of the interviewees are reported in Table 4.

Thematic analysis. Five factors were identified that may be considered 'factors of feasibility' in expanded access: suitability of investigational treatments, the application process, hospital policies, support (or lack thereof) by pharmaceutical companies, and funding and reimbursement arrangements. Below, these themes are discussed one-by-one. 
Table 4 Characteristics of the respondents.

\begin{tabular}{|c|c|c|c|}
\hline Country & $\begin{array}{l}\text { The Netherlands } \\
(n=14)\end{array}$ & $\begin{array}{l}\text { Turkey } \\
(n=9)\end{array}$ & $\begin{array}{l}\text { United } \\
\text { States } \\
(n=13)\end{array}$ \\
\hline \multicolumn{4}{|l|}{ Gender-no. (\%) } \\
\hline - Male & $8(57.1)$ & $9(100)$ & $7(53.8)$ \\
\hline - Female & $6(42.9)$ & $0(0.00)$ & $6(46.2)$ \\
\hline \multicolumn{4}{|c|}{ Medical specialism-no. (\%) } \\
\hline - Internal medicine & $2(14.3)$ & $0(0.00)$ & $1(7.70)$ \\
\hline - Oncology & $4(28.6)$ & $0(0.00)$ & $3(23.1)$ \\
\hline - Haematology & $3(21.4)$ & $7(77.8)$ & $5(38.5)$ \\
\hline - Psychiatry & $2(14.3)$ & $2(22.2)$ & $0(0.00)$ \\
\hline $\begin{array}{l}\text { - Neurology/ } \\
\text { neurosurgery }\end{array}$ & $3(21.4)$ & $0(0.00)$ & $3(23.1)$ \\
\hline - Surgery & $0(0.00)$ & $0(0.00)$ & $1(7.70)$ \\
\hline \multicolumn{4}{|c|}{ Type of hospital-no. (\%) } \\
\hline $\begin{array}{l}\text { - Community/ } \\
\text { public }\end{array}$ & $5(35.7)$ & $0(0.0)$ & $4(30.8)$ \\
\hline - Academic & $9(64.3)$ & $6(66.7)$ & $8(61.5)$ \\
\hline - Private & $0(0.00)$ & $3(33.3)$ & $1(7.70)$ \\
\hline \multicolumn{4}{|c|}{ Geographical location of practice-no. (\%) } \\
\hline - The Netherlands & $14(100)$ & $\mathrm{N} / \mathrm{a}$ & $\mathrm{N} / \mathrm{a}$ \\
\hline - Istanbul & $\mathrm{N} / \mathrm{a}$ & $3(33.3)$ & $\mathrm{N} / \mathrm{a}$ \\
\hline \multicolumn{4}{|l|}{ European side } \\
\hline - Istanbul & $\mathrm{N} / \mathrm{a}$ & $3(33.3)$ & $\mathrm{N} / \mathrm{a}$ \\
\hline \multicolumn{4}{|l|}{ Anatolian side } \\
\hline - Ankara & $\mathrm{N} / \mathrm{a}$ & $3(33.3)$ & $\mathrm{N} / \mathrm{a}$ \\
\hline - New York & $\mathrm{N} / \mathrm{a}$ & $\mathrm{N} / \mathrm{a}$ & $9(69.2)$ \\
\hline - Other US cities & $\mathrm{N} / \mathrm{a}$ & $\mathrm{N} / \mathrm{a}$ & $4(30.8)$ \\
\hline
\end{tabular}

Suitability of investigational treatments. The attitudes of Dutch and American respondents towards expanded access to investigational drugs were not always favourable; for some as a matter of principle, for others attitudes varied with characteristics of investigational treatments. Respondents mentioned a lack of clinical evidence for the effectiveness of some investigational treatments as a primary factor withholding them from resorting to expanded access. They pointed out that the lack of evidence leads to genuine doubts about the effectiveness as well as the safety of the treatments. Some physicians felt that they should therefore not present expanded access to investigational drugs to their patients as an option. One respondent said: "I think we should think very intelligently about drugs, indications, in- and exclusion criteria and how meaningful that actually is. (...) We have to make sure that it is responsible and safe" (internistoncologist 1, the Netherlands). We did not find this argument with the Turkish physicians. However, most Turkish physicians reported experiences with expanded access to drugs that had already been approved for marketing in the US or in Europe. At that stage, more information about effectiveness and safety of the drug is available from data in other countries.

Dutch and American respondents were also concerned about potential harms. They argued that the acceptability of expanded access to investigational drugs depends on the individual situation of the patient: when patients are facing a progressive or lifethreatening disease, the bar for evidence of expected benefit might be lower than for patients who are (for the moment) in a relatively good condition. For the former, the effectiveness of treatments might be less than can be expected on the basis of clinical trials, as expanded access, as an ultimum remedium, does not maintain as strict criteria of eligibility as clinical trials. This group may also be more severely affected by the side effects. Potential benefits may not outweigh potential harms. A respondent told us: "Because we have these criteria [in a clinical trial], we have isolated the group of patients who we think are the most vulnerable, and unlikely to benefit (...) So we will not offer the treatment to that patient population" (neurologist 1, United States).

Others were sceptical towards the expected effectiveness of unapproved drugs. In particular, Dutch oncologists argued that investigational drugs rarely save lives. One of our Dutch respondents argued: "In the history of oncology we have thought many times-on the basis of phase I, phase II and even randomized phase II trials-that a major breakthrough would occur (...) [which] turned out not to be true; a phase III trial may fail, or give worse outcomes" (internist-oncologist 1, the Netherlands). In some respondents, this led to a categorical rejection of expanded access. Some Dutch oncologists, on the other hand, felt that when new drugs are very effective, they will be available on the market within a reasonable amount of time, and so, applying for expanded access is not worth the effort: "This happens almost never [I almost never feel the need to pursue expanded access], because I know, if there is a good new drug for cancer, market access will follow very soon" (internist-oncologist 2, the Netherlands). Strikingly, this argument was not brought forward in the American or Turkish interviews, and was not brought up by oncologists in these countries.

The application process. Respondents from all three countries indicated that regulatory authorities have crucial roles to play in physicians deciding to embark upon expanded access to investigational drugs. Some report that (perceived) regulations prevent them from prescribing investigative drugs. One of our respondents told us that obtaining approval was "nearly impossible in the few cases that we tried" (haematologist 1, United States). In both the Netherlands and Turkey, respondents were worried about legal consequences of deviating from clinical guidelines and pursuing expanded access: "Yes, we are free to do [expanded access], but (...) legal issues restrict your opinions or your attitudes as well. Generally, we are trying to follow the guidelines because in case of legal issues, you have to show your proof or show your guideline" (haematologist 1, Turkey).

Gaining approval for expanded access to investigational drugs was described by respondents from the Netherlands and the United States as a long and difficult process. Also, they mentioned capacity problems and a shortage of time as reasons not to pursue expanded access. They point out that the process requires (much) paperwork, and the pathways to follow in order to get access are complex. As such, the procedure takes a lot of time, which is not available in already strained healthcare systems: "The tempo, time and energy are the greatest problems of all, because [as a doctor], you just want to be at the bedside" (pulmonologist-oncologist 1, Netherlands).

Hospital policies. Dutch and American respondents indicated that the institutions they work for play an important role in either facilitating or hindering expanded access to investigational drugs. Some respondents report that they are actively withheld from prescribing investigational drugs by hospital management, and resources are directed towards clinical trials instead. An American respondent mentioned lack of institutional support as a major factor hampering the uptake of early access programmes: "In urgent circumstances, we can try to procure via [compassionate use] in life-threatening circumstances. (...) But then there are still a handful of times where I would really like to have investigational agents available if there was a more streamlined mechanism" (haematologist 2, United States).

Respondents in all countries indicated prior experience and institutional policies within hospitals as a major factor facilitating expanded access to investigational drugs. Vice versa, American 
and Dutch respondents indicated a general lack of knowledge about or familiarity with expanded access as a hampering factor, for themselves or for their colleagues: "Many doctors probably do not even know that it is an option to use expanded access. (...) These things tend to happen in large academic medical centres. And that is not where most people (...) get their care" (internist-gastroenterologist 1, United States). Respondents in The Netherlands pointed towards the hospital pharmacist as a source of knowledge about requests for expanded access, who can play a significant role in facilitating this for physicians: "I do not know all procedures [for expanded access] but if I know there is a drug available, I will go to the pharmacy and ask how we can solve this (...) and they will solve it" (internist-oncologist 3 , the Netherlands).

Turkish respondents brought up very different experiences, describing much-more streamlined request processes, involving lesser administrative burdens, with specialized, dedicated nurses who make practical arrangements and facilitate physicians in requesting access to investigational drugs. Lack of experience plays a less distinctive role: "For those who are not already much familiar with the procedure it may take one hour to prepare the application, but [in] our centre, one of the biggest in Turkey, we have lots of patients. (...) So, we have a separate person who is taking care of this communication with the Ministry of Health (...) He just enters the diagnosis and he sends in a brief summary of the disease and then we [provide] the necessary evidence and the literature" (haematologist 2, Turkey).

Pharmaceutical companies. Dutch and American respondents with experience with expanded access to investigational drugs indicated that, while some pharmaceutical companies are very helpful in providing expanded access, other companies offer very limited support. One of our respondents told us: "There is absolutely no support [from industry] if you want to do expanded access. They discourage us, so you have to do it all yourself" (internist-oncologist 1, United States).

Others indicated that, in general, pharmaceutical companies were willing to collaborate with physicians and provide investigational drugs free of charge outside of a research setting. A respondent says: "And the drug company always says that if the insurance companies won't pay for it, we have compassionate use. This we do all the time. The drug companies will pay, if the insurance company won't" (neurologist 2, United States). Others indicate that pharmaceutical companies provide additional support in other ways, for example by handling documentation with the FDA: "I don't need to directly contact the FDA; the company does it" (haematologist 2, United States). These arguments were not seen in the Turkish respondents, who often deal with the Turkish Social Security Institute rather than with pharmaceutical companies directly.

Funding and reimbursement. American respondents brought up funding as an important theme; not (only) the cost of the investigational drug itself, which may be provided free of charge by the manufacturer, but rather the time and materials required for its preparation by the hospital pharmacy, travelling costs for the patient and family members, and the administration, monitoring, pharmacovigilance and data collection involved. Not all patients would be able to afford the ancillary costs associated with expanded access to investigational drugs, American respondents held. American respondents took patients' capacity to pay into account when discussing - and deciding whether or not to bring up-options for expanded access. "The patient has to have resources, too. Not everybody can just get a plane ticket and go to Texas and stay there for six weeks to get the radiation treatment" (head-and-neck surgeon 1, United States).
Turkish respondents pointed out that the Turkish healthcare system offers routine reimbursement of investigational drugs based on scientific evidence and/or regulatory approvals in other regions: "Turkey (...) compensates or reimburses any kind of drug that is available if there's evidence that it works and if it is approved somewhere (else). Not even solely by the FDA or EMA, but also (by) the Japanese Medical Agency" (haematologist 2, Turkey).

In the US on the other hand, reimbursement is far from standard: "Insurance companies may, for instance, refuse to pay for something because it is considered investigational. (...) There are plenty of things that insurance companies consider investigational, but physicians now consider to be standard of care. There is usually a lag before they want to be covering that treatment and that's understandable" (head-and-neck surgeon 1, United States). This means that patients themselves have to pay for the inhospital costs associated with expanded access to investigational drugs, or sometimes their private health insurance may offer some form of reimbursement for ancillary costs.

In the Netherlands, pharmaceutical companies sometimes provide expanded access to investigational drugs free of charge, but it is not customary for hospitals to charge patients for ancillary costs, and reimbursement of ancillary costs is often not possible within the system of government-defined insurable treatments. In Dutch healthcare, offering care that is not covered by national health insurance and having patients pay for uninsured care out of pocket, is not considered (ethically) acceptable. Respondents suggested that this is one of the reasons why individual doctors may be unwilling or unable to provide expanded access and hospitals have policies in place to discourage it.

Some respondents also expressed additional concerns about sustained availability of the drug after it is eventually approved and becomes commercially available, while health insurers may not (yet) reimburse it. If there is a possibility that the drug might not be continuously accessible to their patients, some physicians become hesitant to put them on the drug through expanded access in order to avert unexpected costs in the future.

\section{Discussion}

While our respondents worked in fields in which they would surely care for patients with unmet medical needs that cannot be satisfied using approved treatment regimens, most of them had little experience with expanded access to investigational drugs. For our respondents, expanded access seems to be a theoretical possibility, but not always a practically feasible option in clinical practice. Regulations allow physicians to prescribe unapproved drugs in exceptional circumstances, but whether treating physicians actually do so, depends on various factors. Some factors are associated with individual actors, including treating physicians, pharmaceutical companies and payers. Additional factors are more cultural and moral in nature, for instance: Do doctors have positive or negative attitudes towards expanded access to investigational drugs? When do they consider evidence of efficacy to be satisfactory in relation to possible safety risks? Are they working within a culture in which expanded access is considered relatively standard practice, or are they not? Other factors are associated with structural and practical constraints, including funding policies and organizational structures within hospitals to support and facilitate expanded access. These factors differ between individual countries. Below, we will discuss these factors and relate them to the structural characteristics of the different healthcare systems in general and provisions for expanded access in particular.

The degree of familiarity with the process of using unapproved drugs outside the context of clinical trials in Turkey is 
understandable given the time lag between marketing authorization elsewhere and marketing authorization in Turkey for many drugs. As Turkish regulatory approval is often multiple years behind marketing authorization by the FDA and EMA, with a median gap of 1217 calendar days in the period 2012-2015 (Mashaki Ceyhan et al., 2018), the need for expanded access to unapproved treatments may be higher. This time lag may also explain why we found few concerns regarding the safety and efficacy of the investigational treatments: most treatments offered through expanded access programmes in Turkey are already standard of care in the US or in the Netherlands. Our Turkish respondents were actively taking part in international scientific conferences and thus well aware of newly approved treatments in the US, Europe or elsewhere. This awareness, coupled with routine state reimbursement of expanded access, might help explain the high uptake of expanded access programmes in Turkey. In Turkey, the practicalities concerning expanded access to investigational drugs are often taken care of, as physicians deal with the authorities directly rather than with pharmaceutical companies as is the case in many other countries, and it is probably therefore expanded access to investigational drugs is considered more of a practical option in clinical practice than in the other countries discussed.

In the US, whether or not physicians discuss expanded access to investigational drugs with their patients, seems largely determined by practical constraints, which may not be (seriously) affected by recent legislative changes introduced by the 21 st Century Cures Act and the Right-to-Try Act.

One of the main barriers to the use of investigational drugs outside of clinical trials seems to be limited interest from pharmaceutical companies. This was reported in a chapter by Gerasimov and colleagues, as well (Gerasimov et al., 2020). Additionally, physicians lack knowledge and capacity to request expanded access, as well as time, and are not provided with time or support by their institutions. As was discussed in another empirical report investigating the perspectives of paediatric oncologists (Moerdler et al., 2019), both knowledge and (institutional) support systems are needed to make expanded access happen. That these support systems are not in place, could possibly be explained by the fact that there are few questions from physicians to devise such policies or arrange support, as expanded access is used rather rarely. While a theoretical possibility, expanded access does not seem to be pursued easily by our American respondents. In the US, this is grounded more in practical constraints, such as reimbursement and organizational support, than in the moral concerns that we observed in the Netherlands.

Nonetheless, in the Netherlands, practical constraints still seem to be the main obstacle to expanded access, especially lack of funding. Also, the Dutch healthcare system is characterized by its moral commitment to solidarity and equitable access to health care. Furthermore, Dutch physicians are well-organized and wellconnected in scientific associations that issue national clinical guidelines based on expert consensus. Membership of a scientific association is a requirement to practice in a medical specialty in the Netherlands. Some respondents would, as a matter of principle, not diverge from guidelines issued by their association. This argument seemed particularly prominent in the-tightly knitoncological specialty. Clinical guidelines, which do not incorporate investigational drugs, are highly regarded and generally applied by oncologists. This may explain the hesitant stance found among Dutch oncologists. Finally, we found the principled standpoint among Dutch physicians that if a drug is not approved for marketing, it should not be prescribed at all. Further research is required to better understand and assess the ethical rationales underlying these (negative) principled standpoints regarding expanded access to investigational treatments.
In sum, this study suggests that in all three countries, physicians were hindered in pursuing expanded access to investigational drugs by lacking support from pharmaceutical companies, lack of knowledge about the possibilities, and burdensome application processes.

While clear attempts have been made around the world, both in Europe and the United States, to introduce legal provisions allowing expanded access under strict conditions, it is not widely regarded as a day-to-day option in clinical practice, even when these conditions are met, and the uptake remains relatively low. Even though in the United States there have been widespread public discussions on expanded access to investigational drugs in the run-up to the passing of the Right-to-Try Act and the 21st Centuries Cures Act, expanded access is not widely adopted by clinical practitioners. Right-to-Try should not be seen as a form of expanded access, but rather as an ethically controversial alternative to expanded access, which lacks the kind of oversight that provided by the FDA for expanded access programmes (Borysowski and Górski, 2019). In an empirical report on the perspectives of American oncologists on the Right-to-Try pathway, the practicality of the legislation was questioned, and oncologists expressed concerns about safety, the lack of provision for data collection, and the generation of false hope among patients (Smith et al., 2021). It should be noted that our study was concluded in 2016, before recent regulatory changes took place. However, the new laws may not have resulted in major changes in practices or practicality of expanded access-so far. While the Right-to-Try Act aims to make investigational drugs available to a wider range of patients, it does not oblige companies to supply investigational drugs (Rubin, 2015; Holbein et al., 2015; BatemanHouse and Robertson, 2018), nor does it require treating physicians to pursue or cooperate with expanded access requests for their patients.

Some factors can be addressed relatively easily, for instance by improving the information that pharmaceutical companies supply about the (im)possibilities of using their investigational drugs via expanded access programmes. This may be done by introducing a formal obligation for pharmaceutical companies to inform physicians about expanded access to their investigational drugs (Buckley and O'Neil, 2020), and, as suggested elsewhere, by mandating the development of expanded access policies (Kearns et al., 2021). In the United States, the 21st Century Cures act compels pharmaceutical companies to be transparent about their policies for expanded access and to supply such information to stakeholders (Goble, 2018). In Europe, as in the rest of the world, policies like these remain lacking. In addition, the application process can be facilitated by reducing the paperwork needed. Regulatory authorities might wish to consider following the example of the Dutch Health Inspectorate (IGJ, 2020a, 2020b) and the FDA (2018), which have streamlined the processes of applying for expanded access and made it more feasible for treating physicians to pursue it. Further improvements could lie in improving the knowledge of physicians about expanded access regulations and the practical possibilities through extra training and additional informational resources for treating physicians, as has been suggested elsewhere (Darrow et al., 2015; Moerdler et al., 2019; Gerasimov et al., 2020; Bunnik et al., 2021).

Other factors are more difficult to address, especially factors regarding the willingness of pharmaceutical companies to supply investigational drugs via expanded access. How could companies be incentivised to supply unapproved drugs to patients in need? One option could be to look at the costs of expanded access for pharmaceutical companies. It has been suggested that some form of reimbursement could render expanded access a more feasible option for pharmaceutical companies (Caplan and BatemanHouse, 2015; Jerome et al., 2016; Bunnik et al., 2018). 
Pharmaceutical companies may be incentivised even further when they are allowed to charge the actual costs of expanded access at this moment.

This interview study suggests that physicians may not engage in expanded access when it does not seem feasible. If they feel uncertain whether they will succeed in obtaining a drug through an expanded access programme, they may not pursue it. This means that not all patients who are potentially eligible for expanded access, will be offered the opportunity to try to pursue it. This merits further analysis from an ethical point of view.

Other possible future research could focus on investigating and evaluating healthcare system-specific implementation of the facilitating factors identified in this study. Moreover, empirical research on the experiences and perspectives of other stakeholders, including patients, pharmaceutical companies, hospital managers, health insurers and health authorities could help identify additional factors facilitating or hampering expanded access to investigational treatments in practice.

Limitations. There are several limitations to this study, which was aimed at identifying factors that affect the feasibility of expanded access in practice. It is important to note that our samples are not representative of the total population of medical specialists in either of the three countries included in this study, which means that we might not have found all factors that may facilitate or hinder expanded access to investigational drugs. We specifically recruited respondents that had prior experience with expanded access. Our goal was to understand the range of experiences that physicians might have had with expanded access to investigational drugs to identify factors that may facilitate or hinder the pursuit of expanded access and that cut across different healthcare settings, which are governed and guided by different regulations and different cultures. We were able to include diverse views towards expanded access and to reach saturation in the Dutch and American samples. For pragmatic reasons, most of our US respondents worked in hospitals in New York City, as we were in that city on a research visit. However, we also purposively recruited physicians from other US states, whom we interviewed over Skype in the months following our research visit to the US, until saturation was reached. In Turkey, a limiting factor is that respondents were recruited by our private partner, which may have introduced bias. We were able to include fewer participants than in the US and the Netherlands, and participants were of less diverse medical specialties. However, we were able to include Turkish physicians from various types of hospitals in two different cities, and we feel that, for the purposes of this study, we were able to adequately map a broadthough probably not exhaustive-range of Turkish physicians' experiences with expanded access.

Although we tried to include a wide range of physicians in different hospitals and specializations, our sample is likely biased positively towards expanded access. Physicians who have more experience with expanded access might have been more likely to be reached through snowballing or to reply to our invitation and could have more positive experiences with expanded access, which could paint a biased image of expanded access. Yet these respondents, with more experience using expanded access, will also have been best-positioned to provide insights into factors that facilitate or hinder expanded access in practice. Other physicians might have experienced more knowledge gaps and practical hurdles in pursuing expanded access. using urther research could focus on quantitative measurements of the factors of feasibility identified in this study, or on comparative analyses of practices of expanded access to investigational drugs in different healthcare systems.

\section{Conclusion}

While provisions have been made to allow expanded access to investigational drugs in all three healthcare systems assessed, the theoretical possibility of expanded access did not always correlate with its observed practical feasibility. This study is the first to point out factors of feasibility for expanded access in different healthcare systems around the world, that determine whether or not expanded access is a real and relevant treatment option for physicians in different medical specialties who are treating patients with unmet medical needs. The most important factors in all systems assessed are practical hurdles, including lack of knowledge of and familiarity with expanded access, the time and effort required for the request process, willingness or ability of pharmaceutical companies to supply the drugs, and funding issues. Especially in the United States and the Netherlands, lack of reimbursement for expanded access may withhold physicians from pursuing expanded access for their patients. Facilitating factors include a streamlined process within the healthcare institution, including specialised personnel tasked with the administrative duties associated with requesting expanded access, support from hospital management, and routine reimbursement of expanded access. Closing the gap between theoretical possibility and practical feasibility of expanded access by strengthening policy and support systems in hospitals and solving reimbursement issues at the level of the national health care system will be vital to allow physicians to actually prescribe these investigational drugs to those who need them.

\section{Data availability}

The datasets generated and/or analysed during the current study are not made publicly available in order to protect the privacy of individual participating physicians. In addition, interview transcripts and recordings may contain identifying information about individual physicians, their treatment-decisions, and institutional practices that was provided on condition of anonymity. Reasonable requests for the datasets created during and/or analysed during the current study will be evaluated by the corresponding author on a case-by-case basis.

Received: 22 June 2021; Accepted: 11 October 2021; Published online: 17 November 2021

\section{References}

Agarwal R, Saltz LB (2020) Understanding the right to try act. Clin Cancer Res 26(2):340-343. https://doi.org/10.1158/1078-0432.CCR-19-2015

Agence Nationale de Sécurité du Médicament et des produits de santé (ANSM) (2019) Annual report 2018. https://ansm.sante.fr/var/ansm_site/storage/ original/application/4a4914f30cd19e61213177e4d06fd1e4.pdf. Accessed 17 Feb 2021

Bateman-House A, Robertson CT (2018) The federal right to try act of 2017-a wrong turn for access to investigational drugs and the path forward. JAMA Intern Med 178(3):321-322. https://doi.org/10.1001/jamainternmed.2017.8167

Borysowski J, Górski A (2019) Compassionate use of unauthorized drugs: legal regulations and ethical challenge. Eur J Intern Med 65:12-16. https://doi.org/ 10.1016/j.ejim.2019.04.008

Borysowski J, Ehni H-J, Górski A (2017) Ethics review in compassionate use. BMC Med 15(1):136. https://doi.org/10.1186/s12916-017-0910-9

Bradley EH, Curry LA, Devers KJ (2007) Qualitative data analysis for health services research: developing taxonomy, themes, and theory. Health Serv Res 42(4):1758-1772. https://doi.org/10.1111/j.1475-6773.2006.00684.x

Buckley M, O'Neil C (2020) The practice of pharmaceutics and the obligation to expand access to investigational drugs. J Med Philos 45(2):193-211. https:// doi.org/10.1093/jmp/jhz038

Bunnik EM, Aarts N (2021) The role of physicians in expanded access to investigational drugs: a mixed-methods study of physicians' views and experiences in the Netherlands. J Bioeth Inq 18(2):319-334. https://doi.org/10.1007/ s11673-021-10090-7 
Bunnik EM, Aarts N, van de Vathorst S (2018) Little to lose and no other options: ethical issues in efforts to facilitate expanded access to investigational drugs. Health Policy 122(9):977-983. https://doi.org/10.1016/j.healthpol.2018.06.005

Caplan A, Bateman-House A, Waldstreicher J, Fedor L, Sonty R, Roccia T, Ukropec J, Jansson R (2019) A pilot experiment in responding to individual patient requests for compassionate use of an unapproved drug: the compassionate use advisory committee (compac). Ther Innov Regul Sci 53(2):243-248. https://doi.org/10.1177/2168479018759659

Caplan AL, Bateman-House A (2015) Should patients in need be given access to experimental drugs? Expert Opin Pharmacother 16(9):1275-1279. https:// doi.org/10.1517/14656566.2015.1046837

Centers for Medicare \& Medicaid Services (CM\&MS) (2019) National health expenditures 2018 highlights. https://www.cms.gov/Research-Statistics-Dataand-Systems/Statistics-Trends-and-Reports/NationalHealthExpendData/ NationalHealthAccountsHistorical. Accessed 17 Feb 2021

Centraal Bureau voor de Statistiek (CBS) (2020) Zorguitgaven stegen in 2019 met 5,2 procent (In Dutch) https://www.cbs.nl/nl-nl/nieuws/2020/24/zorguitgavenstegen-in-2019-met-5-2-procent. Accessed 17 Feb 2021

Chapman, Riley C, Moch KI, McFadyen A, Kearns L, Watson T, Furlong P, Bateman-House A (2019) What compassionate use means for gene therapies. Nat Biotechnol 37(4):352-355. https://doi.org/10.1038/s41587-019-0081-7

Code of Federal Regulations (CFR) (2020) Subpart I-expanded access to investigational drugs for treatment use https://www.govinfo.gov/content/pkg/CFR2012-title21-vol5/xml/CFR-2012-title21-vol5-part312-subpartI.xml. Accessed 16 Feb 2021

College ter Beoordeling van Geneesmiddelen (CBG) (2021) Compassionate use programma [In Dutch]. https://www.cbg-meb.nl/onderwerpen/hv-compassionateuse-programma. Accessed 17 Febr 2021

Darrow JJ, Sarpatwari A, Avorn J, Kesselheim AS (2015) Practical, legal, and ethical issues in expanded access to investigational drugs. New Engl J Med 372(3):279-286. https://doi.org/10.1056/NEJMhle1409465

De Visser E (2016) Arts helpt patiënten aan experimentele pillen|De Volkskrant (In Dutch). https://www.volkskrant.nl/wetenschap/arts-helpt-patienten-aanexperimentele-pillen be79e57c/. Accessed 17 Feb 2021

Falit BP, Gross CP (2008) Access to experimental drugs for terminally ill patients. JAMA 300(23):2793-2795. https://doi.org/10.1001/jama.2008.828

Food and Drug Administration (FDA) (2016) Charging for investigational drugs under an IND-questions and answers: guidance for industry. https:// www.fda.gov/media/85682/download. Accessed 17 Feb 2021

Food and Drug Administration (FDA) (2018) Statement from FDA commissioner Scott Gottlieb, M.D., on new efforts to strengthen FDA's expanded access program. https://www.fda.gov/news-events/press-announcements/statementfda-commissioner-scott-gottlieb-md-new-efforts-strengthen-fdas-expandedaccess-program. Accessed 17 Feb 2021

Food and Drug Administration (FDA) (2020) Expanded access (compassionate use) submission data. https://www.fda.gov/news-events/expanded-access/ expanded-access-compassionate-use-submission-data. Accessed 17 Feb 2021

Gerasimov E, Donoghue M, Bilenker J, Watt T, Goodman N, Laetsch TW (2020) Before it's too late: multistakeholder perspectives on compassionate access to investigational drugs for pediatric patients with cancer. Am Soc Clin Oncol Educ Book 40(1):1-10. https://doi.org/10.1200/EDBK_278995

Gertel A (2017) Preapproval access and right-to-try initiatives: what are we willing to give up? Ther Innov Regul Sci 51(2):164-169. https://doi.org/10.1177/ 2168479016680254

Glaser BG, Strauss AL (2017) The discovery of grounded theory: strategies for qualitative research, 1 st edn. Routledge.

Goble JA (2018) The potential effect of the 21st century cures act on drug development. J Manag Care Spec Pharm 24(7):677-681. https://doi.org/10.18553/ jmcp.2018.24.7.677

Holbein MEB, Berglund JP, Weatherwax K, Gerber DE, Adamo JE (2015) Access to investigational drugs: FDA expanded access programs or "Right-to-Try" legislation? Clin Transl Sci 8(5):526-532. https://doi.org/10.1111/cts.12255

Inspectie Gezondheidszorg en Jeugd (IGJ) (2020a) Wijzigingen bij verzoek tot levering op artsenverklaring' (In Dutch). Nieuwsbericht. Ministerie van Volksgezondheid, Welzijn en Sport. https://www.igj.nl/actueel/nieuws/2020/ 06/08/wijzigingen-bij-verzoek-tot-levering-op-artsenverklaring. Accessed 17 Feb 2021

Inspectie Gezondheidszorg en Jeugd (IGJ) (2020b) Leveren Op Artsenverklaring (in Dutch) https://www.igj.nl/zorgsectoren/geneesmiddelen/geneesmiddelenzonder-handelsvergunning/leveren-op-artsenverklaring. Accessed 17 Feb 2021

Jarow JP, Lemery S, Bugin K, Khozin S, Moscicki R (2016) Expanded access of investigational drugs: the experience of the center of drug evaluation and research over a 10-year period. Ther Innov Regul Sci 50(6):705-709. https:// doi.org/10.1177/2168479016656030

Jerome RN, Edwards TL, Boswell HC, Bernard GR, Harris PA, Pulley JM (2016) Recommendations to facilitate expanded access to investigational therapies for seriously ill Patients. Acad Med 91(3):305-309. https://doi.org/10.1097/ ACM.0000000000000914
Kearns L, Chapman CR, Moch KI, Caplan AL, Watson T, McFadyen A, Furlong P, Bateman-House A (2021) Gene therapy companies have an ethical obligation to develop expanded access policies. Mol Ther 29(4):1367-1369. https:// doi.org/10.1016/j.ymthe.2021.03.008

Kimberly LL, Beuttler MM, Shen M, Caplan AL, Bateman-House A (2017) Preapproval access terminology: a cause for confusion and a danger to patients. Ther Innov Regul Sci 51(4):494-500. https://doi.org/10.1177/2168479017696267

Koçkaya G, Wertheimer AI, Kilic P, Tanyeri P, Vural IM, Akbulat A, Artiran G, Kerman S (2014) An overview of the orphan medicines market in turkey. Value Health Reg Issues 4:47-52. https://doi.org/10.1016/j.vhri.2014.06.009

Kroneman M, Boerma W, van den Berg M, Groenewegen P, de Jong J, van Ginneken E (2016) Netherlands: health system review. Health Syst Transit 18(2):1-240

Mashaki Ceyhan E, Gürsöz H, Alkan A, Coşkun H, Koyuncu O, Walker. S (2018) The Turkish Medicines and Medical Devices Agency: comparison of its registration process with Australia, Canada, Saudi Arabia, and Singapore. Front Pharmacol 9:9. https://doi.org/10.3389/fphar.2018.00009

Moerdler S, Zhang L, Gerasimov E, Zhu C, Wolinsky T, Roth M, Goodman N, Weiser DA (2019) Physician perspectives on compassionate use in pediatric oncology Pediatr Blood Cancer 66(3):e27545. https://doi.org/10.1002/pbc.27545

Organisation for Economic Co-operation and Development (OECD) (2020) Health expenditure and financing. https://stats.oecd.org/Index.aspx?ThemeTreeId=9. Accessed 17 Feb 2021

Rice T, Rosenau P, Unruh LY, Barnes. AJ (2020) United States: health system review. Health Syst Transit 22(4):1-441

Rubin R (2015) Experts critical of America's right-to-try drug laws. Lancet 386(10001):1325-1326. https://doi.org/10.1016/S0140-6736(15)00393-1

Salzman R, Cook F, Hunt T, Malech HL, Reilly P, Foss-Campbell B, Barrett D (2018) Addressing the value of gene therapy and enhancing patient access to transformative treatments. Mol Ther 26(12):2717-2726. https://doi.org/ 10.1016/j.ymthe.2018.10.017

Smith C, Stout J, Adjei AA, Buckner J, Wentworth M, Tilburt J, Master Z (2021) I think it's been met with a shrug:" oncologists' views toward and experiences with rightto-try. J Natl Cancer Inst 113(6):735-741. https://doi.org/10.1093/jnci/djaa137

Tatar M, Mollahaliloğlu S, Sahin B, Aydin S, Maresso A, Hernández-Quevedo. C (2011) Turkey. Health system review. Health Syst Transit 13(6):1-186. xiii-xiv

Tong A, Sainsbury P, Craig J (2007) Consolidated criteria for reporting qualitative research (COREQ): A 32-Item checklist for interviews and focus groups. Int J Qual Health Care 19:349-57. https://doi.org/10.1093/intqhc/mzm042

Van Norman GA (2018) Expanding patient access to investigational drugs. JACC 3(2):280-293. https://doi.org/10.1016/j.jacbts.2017.11.007

Vural EH, Kockaya G, Tanyeri P, Babacan S, Vural İM, Akbulat A, Artıran G, Akar H, Tokaç M, Kerman S (2012) Compassionate medicine-use programmes in Turkey: a report on current status. J Pharm Health Serv Res 3(3):129-134. https://doi.org/10.1111/j.1759-8893.2012.00090.x

Watson T (2017) A global perspective on compassionate use and expanded access. Ther Innov Regul Sci 51(2):143-145. https://doi.org/10.1177/2168479017694848

Wieseler B, McGauran N, Kaiser T (2019) New drugs: where did we go wrong and what can we do better? BMJ (Clin Res Ed.) 366:14340. https://doi.org/10.1136/ bmj.14340

\section{Acknowledgements}

This article is part of the research project 'Nice to meet? Meeting unmet medical needs: a social innovation to facilitate early access to investigational drugs' (grant no. 313-99-311) funded within the Responsible Innovation (MVI) programme of the Dutch Research Council (NWO). myTomorrows is involved in the research project as a private partner. The funding organization and the private partner have not been involved in the design or conduct of the study, the collection, analysis or interpretation of data, or the writing or publication of this manuscript. myTomorrows is an online platform that informs physicians and patients around the world about expanded access and offers expanded access programmes.

\section{Author contributions}

Interviews were conducted by EMB and/or NA. Data was analysed by SFV and EMB. Interpretation of the data was done by SFV, $\mathrm{MH}$ and $\mathrm{EMB}$. Theoretical background was provided by SFV. The paper was drafted by SFV and MH. EMB and NA made substantia contributions including design of the study and revision of the manuscript. All authors read and approved the final manuscript for publication, and agree to be accountable for all aspects of the work.

\section{Competing interests}

The authors declare no competing interests.

\section{Ethical approval}

We received a waiver from the research ethics review committee of Erasmus MC, Rotterdam, the Netherlands (MEC-2016-275), as the research does not fall within the scope of the Dutch Medical Research Involving Human Subjects Act. 


\section{Informed consent}

All interview respondents provided oral informed consent for recording and participation.

\section{Additional information}

Supplementary information The online version contains supplementary material available at https://doi.org/10.1057/s41599-021-00950-3.

Correspondence and requests for materials should be addressed to Eline M. Bunnik.

Reprints and permission information is available at http://www.nature.com/reprints

Publisher's note Springer Nature remains neutral with regard to jurisdictional claims in published maps and institutional affiliations. (c) (i) Open Access This article is licensed under a Creative Commons Attribution 4.0 International License, which permits use, sharing, adaptation, distribution and reproduction in any medium or format, as long as you give appropriate credit to the original author(s) and the source, provide a link to the Creative Commons license, and indicate if changes were made. The images or other third party material in this article are included in the article's Creative Commons license, unless indicated otherwise in a credit line to the material. If material is not included in the article's Creative Commons license and your intended use is not permitted by statutory regulation or exceeds the permitted use, you will need to obtain permission directly from the copyright holder. To view a copy of this license, visit http://creativecommons.org/ licenses/by/4.0/.

(C) The Author(s) 2021 